\title{
molecules
}

ISSN 1420-3049

www.mdpi.com/journal/molecules

Article

\section{Chemical Constituents of the Mexican Mistletoe (Psittacanthus calyculatus)}

Bah Moustapha ${ }^{1}{ }^{*}$, Gutiérrez-Avella Dora Marina ${ }^{1}$, Fuentes-Ordaz Raúl ${ }^{2}$, Castañeda-Moreno Raquel $^{1}$ and Martínez Mahinda ${ }^{2}$

1 Facultad de Química, Universidad Autónoma de Querétaro, Centro Universitario, Cerro de las Campanas, Querétaro 76010, Mexico; E-Mails: domagu@uaq.mx (G.-A.D.M.); raquelito_cm@hotmail.com (C.-M.R.)

2 Facultad de Ciencias Naturales, Universidad Autónoma de Querétaro, Campus Juriquilla, Querétaro 76230, Mexico; E-Mails: rfuentes@cideteq.mx (F.-O.R.); mahinda@uaq.mx (M.M.)

* Author to whom correspondence should be addressed; E-Mails: moubahdia@yahoo.com.mx or moubah@uaq.mx; Tel.: +52-442-192-1200 Ext. 5536; Fax: +52-442-192-1312.

Received: 11 October 2011; in revised form: 4 November 2011 / Accepted: 7 November 2011 / Published: 9 November 2011

\begin{abstract}
A phytochemical study of the methanol-soluble fraction of an aqueous extract of a sample of Psittacanthus calyculatus collected from the host plant Prosopsis laevigata (Smooth Mesquite) using several techniques, including co-chromatography coupled with UV detection, chromatographic purifications and IR, NMR and MS studies, resulted in the identification of gallic acid, two flavonol-3-biosides and the nonprotein amino acid $\mathrm{N}$-methyl-trans-4-hydroxy-L-proline.
\end{abstract}

Keywords: Psittacanthus calyculatus; isorhamnetin bioside; quercetin bioside; trans-4-hydroxy- $N$-methylproline; NMR

\section{Introduction}

Psittacanthus calyculatus (DC.) G. Don (Loranthaceae) is widely used in Mexican traditional medicine for the treatment of cardiovascular diseases, nowadays the leading cause of deaths in Mexico. It is a semi-parasitic plant that grows on a great variety of harvestable plants, wild or cultivated, belonging to the Rutaceae, woody Leguminosae (Fabaceae), Conniferae, Fagaceae, Myrtaceae (Eucaliptus), and Pinaceae families, many of which are fruit trees or timber-yielding plants. 
In Mexico, it is literally most commonly known as "the plants'cancer" and "true mistletoe". It is seen by farmers as a very harmful plant because it is associated with major crop losses and sometimes with the death of the host plants. However, it is used in folk medicine as an antiseptic and as a treatment for hypertension [1], as well as for alopecia [2]. In a pharmacological evaluation of the activity of the aqueous extract of a plant sample collected from Prosopsis laevigata L. (Fabaceae) on isolated rat aorta, our group previously found that it produces a greater vascular vasodilatory effect than that of the classic vasorelaxant acetylcholine [3]. This observation essentially matches another previous report [4]. However, despite its very promising antihypertensive potential, and apart from a preliminary analysis of a few flavonoids in which hesperitin, quercetin and (+)-catechin were identified [3], its phytochemical contents have not been fully documented. Therefore, we report here the identification of two flavonoid biosides, gallic acid, and the alkaloid $N$-methyl-trans-4-hydroxy-L-proline in the methanol soluble fraction of an aqueous extract of the plant.

\section{Results and Discussion}

On account of the important roles phenolic compounds play in promoting health benefits, particularly on the cardiovascular system, the presence of five phenolic acids (gallic, protocatechuic, caffeic, $p$-coumaric, and rosmarinic) and ten flavonoids (hesperidin, rutin, myricetin, luteolin, $(+)$-catechin, quercetin, apigenin, naringenin, hesperetin, and kaempferol) commonly found in plants was investigated in both non hydrolyzed and hydrolyzed aqueous and methanol extracts by the use of an HPLC apparatus coupled with a UV detector. Retention times and co-chromatography were used to assess the correct identification of the phenolic compounds, and the quantification of those identified was achieved using calibration curves. Of all the phenolic standards investigated, besides $(+)$-catechin, hesperitin, rutin, and quercetin, already reported [3], only gallic acid (1) was identified and then quantified in the aqueous extract. The methanol extract contained none of the standards used. Gallic acid was found to be present mainly in the free form, at a level of $26.6 \mathrm{mg} / \mathrm{g}$ of dry plant material (DPM), while an additional low quantity $(0.7 \mathrm{mg} / \mathrm{g}$ DPM $)$ was obtained after acid hydrolysis. (+)-Catechin (2) gave a particularly high yield $(59.3 \mathrm{mg} / \mathrm{g}$ DPM). As evidenced by these results, most of the secondary metabolites of the aqueous extract are unknown. For this reason, a conventional phytochemical study involving chromatographic analyses and purifications, and spectroscopic identification was undertaken. Column chromatography (CC) on Sephadex LH-20 of the methanolsoluble fraction of the aqueous extract followed by HPLC purification led to the isolation of trans 4-hydroxy- $N$-methylproline (3). In addition, two major flavonol glycosides, isorhamnetin 3-O- $\beta$-Dxylopyranosyl $(1 \rightarrow 6)-\beta$-D-glucopyranoside $(4)$ and quercetin-3- $O$ - $\beta$-D-xylopyranosyl $(1 \rightarrow 6)-\beta$-Dglucopyranoside (5) (Figure 1) were also purified from another portion of the methanol fraction, using successive Si-gel CC followed by reversed-phase HPLC. The structures of these three compounds were determined by spectroscopic studies. Many other minor compounds were isolated during the same process. However, their yields were insufficient for further purification and subsequent identification by NMR spectroscopy. Although the NMR data of the compounds 3-5 in other solvents are already reported [5-7], we report here those now obtained in $\mathrm{CD}_{3} \mathrm{OD}$ for compound 3 (see Experimental), and in $\mathrm{C}_{5} \mathrm{D}_{5} \mathrm{~N}$ for compounds 4 and $\mathbf{5}$ (Table 1). 
Figure 1. Compounds identified in the $\mathrm{MeOH}$-soluble fraction of the aqueous extract from a sample of $P$. calyculatus.<smiles>O=C(O)c1cc(O)c(O)c(O)c1</smiles>

(1)<smiles>Oc1cc(O)c2c(c1)OC(c1ccc(O)c(O)c1)C(O)C2</smiles>

(2)<smiles>CN1CC(O)C[C@H]1C(=O)O</smiles>

(3)

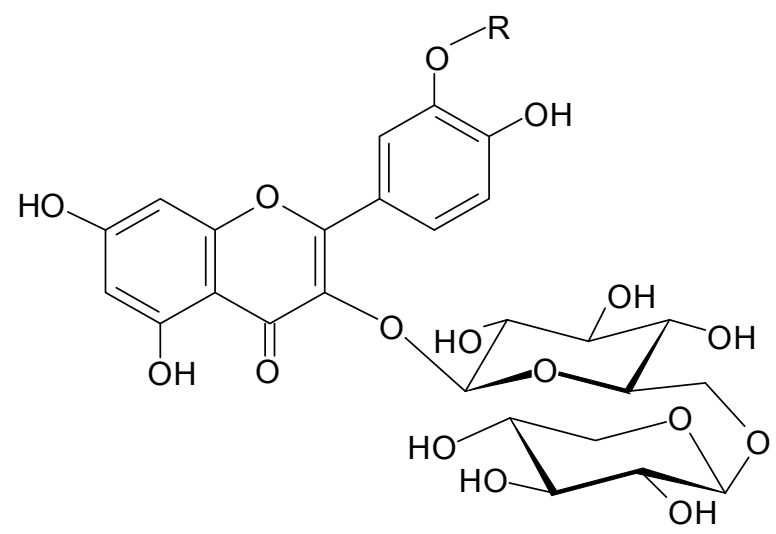

(4) $\mathrm{R}=\mathrm{CH}_{3}$

(5) $\mathrm{R}=\mathrm{H}$

Table 1. ${ }^{1} \mathrm{H}(500 \mathrm{MHz})$ and ${ }^{13} \mathrm{C}-\mathrm{NMR}(125.7 \mathrm{MHz})$ spectral data of compounds 4 and $\mathbf{5}$ (in $\left.\mathrm{C}_{5} \mathrm{D}_{5} \mathrm{~N}\right)$.

\begin{tabular}{|c|c|c|c|c|c|}
\hline \multicolumn{3}{|c|}{4} & \multicolumn{3}{|c|}{5} \\
\hline & $\delta_{H}(J$ in $\mathbf{H z})$ & $\delta_{\mathrm{C}}$ & & $\delta_{H}(J$ in $\mathbf{H z})$ & $\delta_{C}$ \\
\hline 2 & & 157.6 & 2 & & 158.2 \\
\hline 3 & & 134.9 & 3 & & 135.2 \\
\hline 4 & & 178.6 & 4 & & 178.6 \\
\hline 5 & & 162.8 & 5 & & 162.7 \\
\hline 6 & $6.66(\delta, 2.0)$ & 99.9 & 6 & $6.63(\delta, 2.0)$ & 99.8 \\
\hline 7 & & 166.0 & 7 & & 165.9 \\
\hline 8 & $6.73(\delta, 2.0)$ & 94.7 & 8 & $6.62(\delta, 2.0)$ & 94.6 \\
\hline 9 & & 157.7 & 9 & & 157.7 \\
\hline 10 & & 105.6 & 10 & & 105.4 \\
\hline $1^{\prime}$ & & 122.1 & $1^{\prime}$ & & 122.5 \\
\hline $2^{\prime}$ & $8.50(\delta, 2.0)$ & 114.4 & $2^{\prime}$ & $8.37(\delta, 2.0)$ & 117.9 \\
\hline $3^{\prime}$ & & 148.1 & $3^{\prime}$ & & 146.7 \\
\hline $4^{\prime}$ & & 151.3 & $4^{\prime}$ & & 150.7 \\
\hline $5^{\prime}$ & $7.27(\delta, 8.0)$ & 116.3 & $5^{\prime}$ & $7.30(\delta, 8.0)$ & 116.3 \\
\hline $6^{\prime}$ & $7.88(\delta \delta, 8.0,2.0)$ & 123.4 & $6^{\prime}$ & $8.10(\delta \delta, 8.0,2.0)$ & 123.0 \\
\hline $\mathrm{CH} 3 \mathrm{O}$ & $3.95(\sigma)$ & 56.3 & & & \\
\hline Gla-1 & $6.26(\delta, 7.5)$ & 103.8 & Gla-1 & $6.03(\delta, 7.5)$ & 104.2 \\
\hline Gl-2 & $4.28(\delta \delta, 9.0,7.5)$ & 76.1 & Gl-2 & $4.21(\delta \delta, 9.0,7.5)$ & 75.9 \\
\hline Gl-3 & $4.31(\delta \delta, 9.0,9.0)$ & 78.5 & Gl-3 & $4.22(\delta \delta, 9.5,9.0)$ & 78.5 \\
\hline
\end{tabular}


Table 1. Cont.

\begin{tabular}{|c|c|c|c|c|c|}
\hline \multicolumn{3}{|c|}{4} & \multicolumn{3}{|c|}{5} \\
\hline & $\delta_{H}(J$ in $\mathbf{H z})$ & $\delta_{\mathrm{C}}$ & & $\delta_{H}(J$ in $\mathrm{Hz})$ & $\delta_{\mathrm{C}}$ \\
\hline Gl-4 & $4.21(\mathrm{dd}, 10.0,9.0)$ & 71.5 & G1-4 & $4.06(\mathrm{dd}, 9.5,9.5)$ & 71.5 \\
\hline Gl-5 & $4.07(\mathrm{~m})$ & 77.7 & Gl-5 & $4.09(\mathrm{~m})$ & 77.7 \\
\hline Gl-6 & $\begin{array}{l}4.68(\mathrm{dd}, 11.2,2.0) \\
4.19(\mathrm{~m})\end{array}$ & 69.7 & Gl-6 & $\begin{array}{l}4.68(\mathrm{dd}, 11.0,1.5) \\
4.14(\mathrm{~m})\end{array}$ & 69.7 \\
\hline$X y^{a}-1$ & $4.76(\mathrm{~d}, 7.5)$ & 105.6 & $X y^{a}-1$ & $4.82(\mathrm{~d}, 7.0)$ & 105.4 \\
\hline Ху-2 & $3.84(\mathrm{dd}, 8.5,7.5)$ & 74.7 & Xy-2 & $3.88(\mathrm{dd}, 8.5,7.0)$ & 74.7 \\
\hline $\mathrm{Xy}-3$ & $3.96(\mathrm{dd}, 8.5,8.5)$ & 78.0 & Хy-3 & $4.00(\mathrm{dd}, 8.5,8.5)$ & 77.6 \\
\hline $\mathrm{Xy}-4$ & $4.06(\mathrm{ddd}, 10.0,8.5,5.0)$ & 70.9 & Xy-4 & $4.06(\mathrm{~m})$ & 71.0 \\
\hline Хy-5 & $\begin{array}{l}4.18(\mathrm{~m}) \\
3.48(\mathrm{dd}, 11.2,10.2)\end{array}$ & 66.8 & Ху-5 & $\begin{array}{l}4.19(\mathrm{~m}) \\
3.55 \mathrm{dd}(11.0,10.0)\end{array}$ & 66.7 \\
\hline
\end{tabular}

Gallic acid was already reported in P. cucullaris [8]), and (+)-catechin along with tyramine in P. cuneifolius $[9,10]$; however, to the best of our knowledge, this is the first report of the occurrence of compounds 3-5 in the genus Psittachathus. Good anti-inflammatory activity has been recognized for gallic acid [11,12], while quercetin and isorhamnetin, which can be released from their glycosides in physiological conditions, have been shown to produce in vitro vasodilatory effects $[13,14]$ and cardioprotective effects in rats [15-17]. Furthermore, recent studies have found a reduction in blood pressure when hypertensive animals and humans are given food supplemented with quercetin [18], so it is plausible to assert that the two flavonol glycosides $\mathbf{4}$ and $\mathbf{5}$, besides the other phenolics found in the aqueous extract of these plant species, contribute greatly to its hypotensive effect. The effect compound $\mathbf{3}$ might have on any part of the cardiovascular system is as yet unreported.

\section{Experimental}

\subsection{General}

HPLC separations were conducted using a Waters apparatus (Millipore Corp., Waters Chromatography Division, Milford, MA, USA), composed of a 600E multisolvent delivery system equipped with a 486 tunable UV detector. Control of the equipment, data acquisition, processing, and management of the chromatographic information were performed by the Empower 2 software (Waters). NMR spectra were run on Varian Inova NMR spectrometers equipped with $5 \mathrm{~mm}{ }^{1} \mathrm{H}$ and ${ }^{13} \mathrm{C}$ probes and operating respectively at 400 and $100 \mathrm{MHz}$ for compound $\mathbf{3}$, and 500 and $125.7 \mathrm{MHz}$, respectively, for compounds $\mathbf{4}$ and 5, with TMS as the internal standard. Mass and IR spectra were obtained on a VG 7070E and Perkin Elmer 283B spectrometers, respectively.

\subsection{Plant Material}

A whole $P$. calyculatus sample was collected from Prosopsis laevigata, its most common host plant in Querétaro and in all central Mexico. Collection was made at the botanical garden of the Universidad Autónoma de Querétaro. The sample was then dried in an oven set at $45{ }^{\circ} \mathrm{C}$ for 10 days. The dried plant was milled before extraction. 


\subsection{Extraction}

The milled dry plant material (approximately $2 \mathrm{~kg}$ ) was extracted at $60^{\circ} \mathrm{C}$ by stirring it together with $2 \%$ aqueous ethanol $(\mathrm{v} / \mathrm{v})$ (total volume: 5 l) for three days in total darkness. The extract was then freeze-dried.

\subsection{Isolation and Characterization of trans-4-Hydroxy-N-methylproline (3)}

The dry extract was mixed with $\mathrm{MeOH}$ by shaking. The liquid layer was evaporated until dry under reduced pressure. A portion of this $\mathrm{MeOH}$ extract $(0.5764 \mathrm{~g})$ was fractionated in a Sephadex LH-20 column chromatography eluted with this solvent. Seven fractions of $500 \mathrm{~mL}$ were collected. Fraction 3 $(52.25 \mathrm{mg}$ ) was separated isocratically by HPLC using a C-18 column (Symmetry: $300 \mathrm{~mm} \times 19 \mathrm{~mm}$ i.d.; mobile phase: $\mathrm{H}_{2} \mathrm{O}-\mathrm{CH}_{3} \mathrm{CN}$ 6:4; flow rate: $3 \mathrm{~mL} / \mathrm{min}$; $\mathrm{UV}$ detection at $254 \mathrm{~nm}$ ). The most abundant of the five collected compounds $\left(22.42 \mathrm{mg}, t_{\mathrm{R}} 26.39 \mathrm{~min}\right)$ was purified by recycling HPLC to give $3.74 \mathrm{mg}$ of an amorphous white powder that turned slightly brown after a few weeks. Its structural characterization was achieved through its IR, MS, and NMR data. There were characteristic IR (film) bands at $3375 \mathrm{~cm}^{-1}, 2926 \mathrm{~cm}^{-1}$ and $2853 \mathrm{~cm}^{-1}, 1625 \mathrm{~cm}^{-1}\left(v_{\mathrm{as}} \mathrm{COO}^{-}\right), 1400 \mathrm{~cm}^{-1}\left(v_{\mathrm{s}} \mathrm{COO}^{-}\right)$, and $1073 \mathrm{~cm}^{-1}$ (C-N). EIMS gave peaks at m/z $145\left(\mathrm{M}^{+}, 5 \%\right), 100(100 \%), 82,42$ and 18. ${ }^{1} \mathrm{H}-\mathrm{NMR}(400 \mathrm{MHz}$, $\mathrm{CD}_{3} \mathrm{OD}$ ) showed the following signals: $\delta 4.48(\mathrm{~m}, \mathrm{H}-4), 4.05(\mathrm{dd}, J=10.6,7.6 \mathrm{~Hz}, \mathrm{H}-2), 3.78$ (dd, $J=12.8,4.4 \mathrm{~Hz}, \mathrm{H}-5 \alpha), 3.05$ (ddd, $J=12.4,2.0,2.0 \mathrm{~Hz}, \mathrm{H}-5 \beta), 2.98$ (s, $\left.\mathrm{CH}_{3}-\mathrm{N}\right), 2.43$ (dddd, $J=13.6$, 7.6, 2.0, $2.0 \mathrm{~Hz}, \mathrm{H}-3 \alpha$ ), 2.15 (ddd, $J=13.8,11.0$ and $4.8 \mathrm{~Hz}, \mathrm{H}-3 \beta)$, and ${ }^{13} \mathrm{C}-\mathrm{NMR}(100 \mathrm{MHz}$, $\left.\mathrm{CD}_{3} \mathrm{OD}\right)$ gave signals at $\delta 172.8(\mathrm{C}=\mathrm{O}), 71.9(\mathrm{C}-2), 70.9(\mathrm{C}-4), 64.1(\mathrm{C}-5), 44.0\left(\mathrm{CH}_{3}-\mathrm{N}\right)$ and $40.3(\mathrm{C}-3)$.

\subsection{Isolation of Isorhamnetin 3-O- $\beta$-D-xylopyranosyl $(1 \rightarrow 6)$ - $\beta$-D-glucopyranoside (4) and Quercetin 3-O- $\beta$-D-xylopyranosyl $(1 \rightarrow 6)$ - $\beta$-D-glucopyranoside (5)}

A second portion (5.25 g) of the methanol extract was subjected to open CC on Si-gel (J.T.Baker, 60-200 mesh), employing a gradient elution with AcOEt (solvent A) and $\mathrm{MeOH}$ (solvent B), from $100 \%$ to $0 \%$ A. A total of 71 fractions were collected. Fractions $25-34$, eluted with AcOEt-MeOH (95:5), were combined and analyzed by HPLC. Scaling up to semi-preparative HPLC using an XDB-C18 column (ZORBAX) $(21.2 \times 150 \mathrm{~mm} ; 5 \mu \mathrm{m} ; 65 \mathrm{~min}$ of linear gradient elution with aqueous AcOH $0.0125 \mathrm{~N}$ from $100 \%$ to $60 \%$, and $\mathrm{CH}_{3} \mathrm{CN}$; flow rate: $4 \mathrm{~mL} / \mathrm{min}$; detection at $280 \mathrm{~nm}$ ) yielded the two main flavonol glycosides $4\left(8.1 \mathrm{mg} ; t_{\mathrm{R}} 49.55 \mathrm{~min}\right)$ and $\mathbf{5}\left(6.9 \mathrm{mg}, t_{\mathrm{R}} 43.26 \mathrm{~min}\right)$ as slightly yellow amorphous powders. NMR data: see Table 1 .

\section{Conclusions}

Although the vasodilatory effects of the aqueous extract of this medicinal plant was previously described, this is the first phytochemical study reporting the isolation of some of its constituents, most of which could contribute to its hypotensive effect. 


\section{Acknowledgements}

This research was financed by Consejo Nacional de Ciencia y Tecnología (CONACYT), Mexico (Project 47433). We would also like to give thanks to professor Daniel Stauffer, Universidad Autónoma de Querétaro and to professor Liz Rago, Centro de Estudios de Inglés Kennedy S.C., Querétaro, for their contribution in improving the literary style of this article.

\section{References and Notes}

1. Díaz J.L. Usos de las Plantas Medicinales de México. Monografías Científicas II; Instituto Mexicano para el Estudio de las Plantas Medicinales: Mexico City, Mexico, 1976; pp. 17-18.

2. Casas, A.; Viveros, J.L.; Caballero, J. Etnobotánica mixteca. Sociedad, cultura y recursos naturales en la montaña de Guerrero; INI-CONACULTA: Mexico City, Mexico, 1994; pp. 366-367.

3. Ibarra-Alvarado, C.; Rojas, A.; Mendoza, S.; Bah, M.; Gutiérrez, D.M.; Hernández-Sandoval, L.; Martínez, M. Vasoactive and antioxidant activities of plants used in Mexican traditional medicine for the treatment of cardiovascular diseases. Pharm. Biol. 2010, 48, 732-739.

4. Rodriguez-Cruz, M.E.; Perez-Ordaz, L.; Serrato-Barajas, B.E.; Juarez-Oropeza, M.A.; Mascher, D.; Paredes-Carbajal, M.C. Endothelium-dependent effects of the ethanolic extract of the mistletoe Psittacanthus calyculatus on the vasomotor responses of rat aortic rings. J. Ethnopharmacol. 2003, 86, 213-218.

5. Sciuto, S.; Chillemi, R.; Piattelli, M.; Impellizzeri, G. The identification of 4-hydroxy- $N$ methylproline in the red alga Chondria coerulescens-spectral information. Phytochemistry 1983, 22, 2311-2312.

6. Figliuolo, R.; Naylor, S.; Wang, J.; Langenheim, J.H. Unusual nonprotein imino acid and its relationship to phenolic and nitrogenous compounds in Copaifera. Phytochemistry 1987, 26, 3255-3259.

7. Haraguchi, M.; Gorniak, S.L.; Ikeda, K.; Minami, Y.; Kato, A.; Watson, A.A.; Nash, R.J.; Molyneux, R.J.; Asano, N. Alkaloidal components in the poisonous plant, Ipomoea carnea (Convolvulaceae). J. Agric. Food Chem. 2003, 51, 4995-5000.

8. Sinha, A.; Taylor, W.H.; Khan, I.H.; McDaniel, S.T.; Esko, J.D. Glycoside primers of Psittacanthus cucullaris. J. Nat. Prod. 1999, 62, 1036-1038.

9. Graziano, M.N.; Widmer, G.A.; Juliani, R.; Coussio, J.D. Flavonoids from the Argentine mistletoe, Psittacanothus cuneifolius. Phytochemistry 1967, 6, 1709-1711.

10. Graziano, M.N.; Widmer, G.A.; Coussio, J.D.; Juliani, R. Isolation of tyramine from five Argentine species of Loranthaceae. Lloydia 1967, 30, 242-244.

11. Kroes, B.H.; Van den Berg, A.J.J.; Quarles van Ufford, H.C.; Van Dijk, H.; Labadie, R.P. Anti-inflammatory activity of gallic acid. Plant Med. 1992, 58, 499-504.

12. Pal, C.; Bindu, S.; Dey, S.; Alam, A.; Goyal, M.; Iqbal, M.S.; Maity, P.; Adhikari, S.S.; Bandyopadhyay, U. Gallic acid prevents nonsteroidal anti-inflammatory drug-induced gastropathy in rat by blocking oxidative stress and apoptosis. Free Radic. Biol. Med. 2010, 49, 258-267. 
13. Duarte, J.; Perez Vizcaino, F.; Utrilla, P.; Jimenez, J.; Tamargo, J.; Zarzuelo, A. Vasodilatory effects of flavonoids in rat aortic smooth muscle. Structure-activity relationships. Gen. Pharmacol. 1993, 24, 857-862.

14. Duarte, J.; Perez-Vizcaino, F.; Zarzuelo, A.; Jimenez, J.; Tamargo, J. Vasodilator effects of quercetin in isolated rat vascular smooth muscle. Eur. J. Pharmacol. 1993, 239, 1-7.

15. Perez-Vizcaino, F.; Ibarra, M.; Cogolludo, A.L.; Duarte, J.; Zaragoza-Arnaez, F.; Moreno, L.; Lopez-Lopez, G.; Tamargo, J. Endothelium-independent vasodilator effects of the flavonoid quercetin and its methylated metabolites in rat conductance and resistance arteries. J. Pharmacol. Exp. Ther. 2002, 302, 66-72.

16. Han, J.J.; Hao, J.; Kim, C.H.; Hong, J.S.; Ahn, H.Y.; Lee, Y.S. Quercetin prevents cardiac hypertrophy induced by pressure overload in rats. J. Vet. Med. Sci. 2009, 71, 737-743.

17. Zhang, N.-J.; Pei, F.; Wei, H.-Y.; Zhang, T.-T.; Yang, C.; Ma, G.; Yang, C.-L. Isorhamnetin protects rat ventricular myocytes from ischemia and reperfusion injury. Exp. Toxicol. Pathol. 2011, 63, 33-38.

18. Larson, A.J.; Symons, J.D.; Jalili, T. Quercetin: A treatment for hypertension? A review of efficacy and mechanisms. Pharmaceuticals 2010, 3, 237-250.

Sample Availability: Samples of the compounds $\mathbf{3}-\mathbf{5}$ are available from the authors.

(C) 2011 by the authors; licensee MDPI, Basel, Switzerland. This article is an open access article distributed under the terms and conditions of the Creative Commons Attribution license (http://creativecommons.org/licenses/by/3.0/). 